\title{
Elution patterns of rubella IgM, IgA, and IgG antibodies from a dextran and an agarose gel
}

\author{
J. R. PATTISON AND JENNIFER E. MACE
}

From the Departments of Virology, London Hospital Medical College, Turner Street, London E1 2AD and School of Pathology, Middlesex Hospital Medical School, London WI

SYNOPSIS The elution pattern of serum proteins and the distribution of rubella HAI activity in 95 sera from 65 cases were determined after gel filtration with (a) Sephadex G-200 and (b) Bio-Gel A-5M. Rubella HAI antibody in peak 1 after Sephadex G-200 fractionation of early convalescent sera consists of both IgM and high molecular weight IgA. However, these two classes of antibody can be distinguished by gel filtration with Bio-Gel A-5M. Bearing these differences in mind, the results of fractionation with the two gels correlate very well although the use of Bio-Gel A-5M gives a slightly less sensitive technique for the diagnosis of recent infection.

One of the approaches to measuring rubella antibodies of the various immunoglobulin classes is first to separate the immunoglobulins on the basis of differing physical properties and then to use rubella HAI tests to detect specific antibody. The initial separation can be achieved either by sucrose density gradient centrifugation (for example, Best, Banatvala, and Watson, 1969) or by gel filtration using the dextran gel Sephadex G-200 (Gupta, Peterson, Stout, and Murphy, 1971; Pattison and Mace, 1973 and 1975) or the agarose, Bio-Gel A-5M (Bürgin-Wolff, Hernandez, and Just, 1971). The elution pattern of serum proteins from these two gels is distinctly different and yet each forms the basis of a valid technique for diagnosing recent rubella on the basis of the presence of specific IgM (Gupta et al, 1971; Pattison and Mace, 1975; Bürgin-Wolff et al, 1971). This report compares the results of processing sera from 65 cases of recent rubella with the two gels.

\section{Material and Methods}

SER A

Ninety-five serum samples from 65 of the 115 cases of rubella described by Pattison and Mace (1975) were tested. The sera were selected only on the basis that there was sufficient to test by both fractionation procedures.

Received for publication 3 February 1975.
GEL FILTRATION

Fractionation of sera with Sephadex G-200 (Pharmacia (GB) Ltd, London) was performed as previously described (Pattison and Mace, 1975) with a gel bed $42 \mathrm{~cm}$ long by $2.5 \mathrm{~cm}$ cross-sectional diameter equilibrated with $0.02 \mathrm{M}$ tris buffered $0.9 \%$ $\mathrm{NaCl}$ plus $0.1 \%$ sodium azide. Fractionation with agarose was performed by a similar technique except that Bio-Gel A-5M (Bio-Rad Laboratories Ltd, St Albans, Hertfordshire) was substituted for Sephadex G-200, and a $1 \mathrm{ml}$ sample of pretreated serum was fractionated instead of a $0.5 \mathrm{ml}$ sample. In exceptional circumstances $2 \mathrm{ml}$ samples were fractionated. The total protein content of the eluant from the columns was continuously monitored as optical density (OD) at $280 \mathrm{~nm}$ by passing the eluant through a Uvicord II spectrophotometer (LKB Instruments, Croydon, Surrey). Thereafter the eluant was collected as $5 \mathrm{ml}$ fractions at a rate of $15-20 \mathrm{ml}$ per hour.

Concentrations of IgM, IgA, and IgG were measured by radial immunodiffusion using LCPartigen plates (Hoechst Pharmaceuticals, Hounslow, Middlesex) and standards of declared concentration (Hoechst Pharmaceuticals).

Rubella HAI tests incorporating overnight reaction of antigen/fraction mixtures were performed as described by Pattison and Mace (1975). Quantitative representation of the rubella HAI activity of the various peaks was derived as described by Pattison and Mace' (1975). Sensitivity to 2-mercaptoethanol (2-ME) was tested by the method of Caul, Smyth, and Clarke (1974). 
RECIPROCAL RUBELLA HAI TITRE

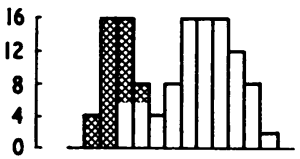

IMMUNOGLOBULINS $\mathrm{mg} / 100 \mathrm{~mL}$.

CONTINUOUS MONITORING O.D. $280 \mathrm{~nm}$.
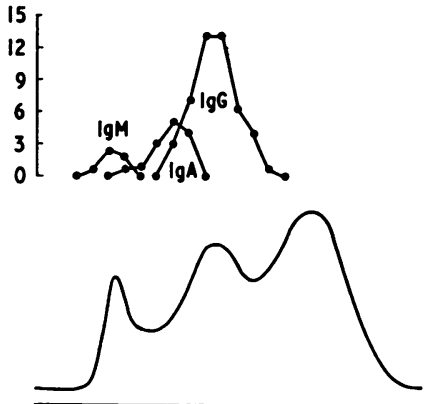

$101214 \quad 16 \quad 18 \quad 202224 \quad 26283032$ Fraction No.

Fig 1 Elution pattern of serum proteins from Sephadex G-200. Hatching denotes sensitivity to 2-ME.

\section{Results}

Figure 1 shows the elution pattern of serum proteins from a column of Sephadex G-200. Serum proteins elute in three peaks from Sephadex G-200, IgM eluting in the first protein peak and IgG in the second. IgA elutes in a broad band overlapping both the IgM and the IgG containing fractions with a greater percentage of the total IgA overlapping the IgG. The serum shown in fig 1 is an early convalescent serum (taken 10 days after the onset of the rash) and, as is typical with such sera, the specific rubella HAI activity elutes in two peaks. The first is coincident with the first protein peak and the $\operatorname{IgM}$ containing fractions and the second with the second protein peak and the IgG containing fractions. However, a part of the latter half of the first peak of rubella HAI activity is resistant to treatment with 2-ME and this 2-ME resistant portion coincides with the forward subfraction of $\operatorname{IgA}$. In contrast to early convalescent sera, the rubella HAI activity of sera from patients with no history of recent rubella elutes only in the second peak after Sephadex G-200 fractionation.

Figure 2 shows the elution pattern from a column of Bio-Gel A-5M of the serum shown in figure 1 . The first detectable protein to elute forms a shallow peak coincident with the IgM peak. This is followed by a more pronounced peak which is not exactly coincident with any immunoglobulin peak since it just precedes the high molecular weight IgA peak. After Bio-Gel A-5M fractionation the bulk of serum

RECIPROCAL

RUBELLA H A I TITRE

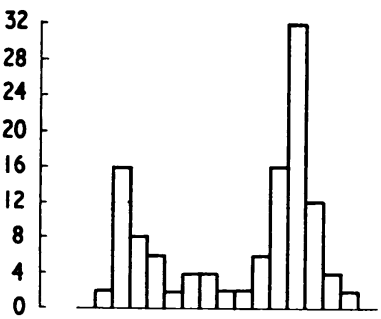

IMMUNOGLOBULINS $\mathrm{mg} / 100 \mathrm{ml}$.

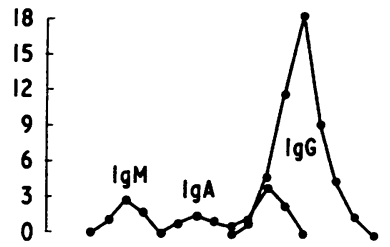

CONTINUOUS MONITORING 0.D. $280 \mathrm{~nm}$.

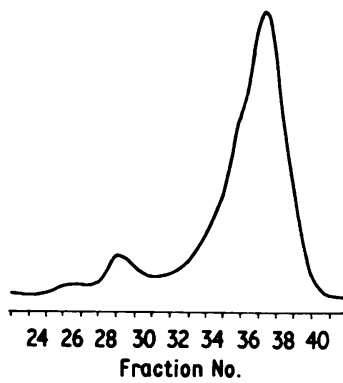

Fig 2 Elution pattern of serum proteins from Bio-Gel A-5M.

protein elutes in a single large peak with a slight shoulder on the leading edge.

Immunoglobulin studies of the fractions after Bio-Gel A-5M show that there is base-line separation of IgM, high molecular weight IgA, and IgG. The rubella HAI activity of early convalescent sera elutes in three peaks associated with these three immunoglobulin peaks (fig 2). In sera from patients with no history of recent rubella all the rubella HAI activity elutes in the third peak.

Testing of 95 convalescent sera from 65 cases of rubella shows that the percentage of the total rubella HAI activity eluting in the first peak after Sephadex G-200 fractionation correlates well over the whole range with the percentage of the total eluting in the IgM and high molecular weight IgA peaks after Bio-Gel A-5M fractionation (fig 3). However, with four sera exhibiting low titre peak 1 rubella HAI activity after G-200 fractionation no HAI activity could be detected in the IgM or high molecular weight IgA fractions after gel filtration with Bio-Gel A-5M unless a $2 \mathrm{ml}$ sample of pretreated serum was applied to the column. 


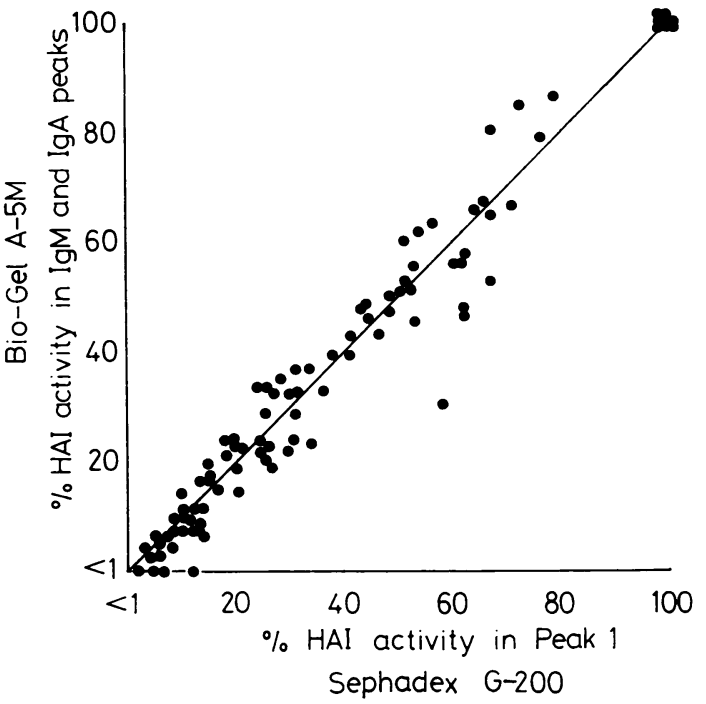

Fig 3 Correlation between results of Bio-Gel A-5M and Sephadex $G-200$ fractionation.

The rubella $H A I$ activity of the various peaks was calculated as a percentage of the total HAI activity. recovered from a column. A $0.5 \mathrm{ml}$ sample was fractionated by Sephadex $G-200$ and a $1.0 \mathrm{ml}$ sample by Bio-Gel A-5M.

The relative contributions of specific IgM antibody and specific high molecular weight IgA antibody in the 95 convalescent sera following fractionation with Bio-Gel A-5M are shown (fig 4). In those sera with specific IgM antibody titres of 1 in 160 or

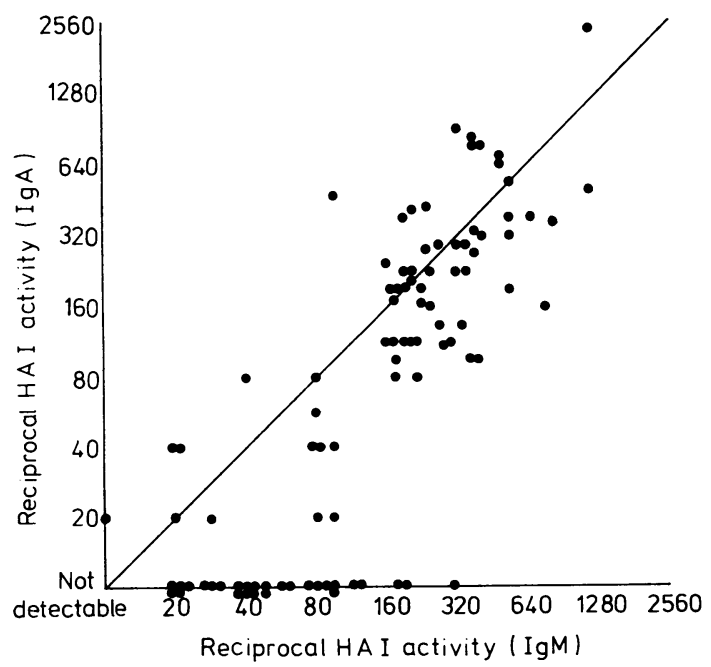

Fig 4 Relation between IgM and high molecular weight IgA rubella HAI activity after Bio-Gel A-5M fractionation.

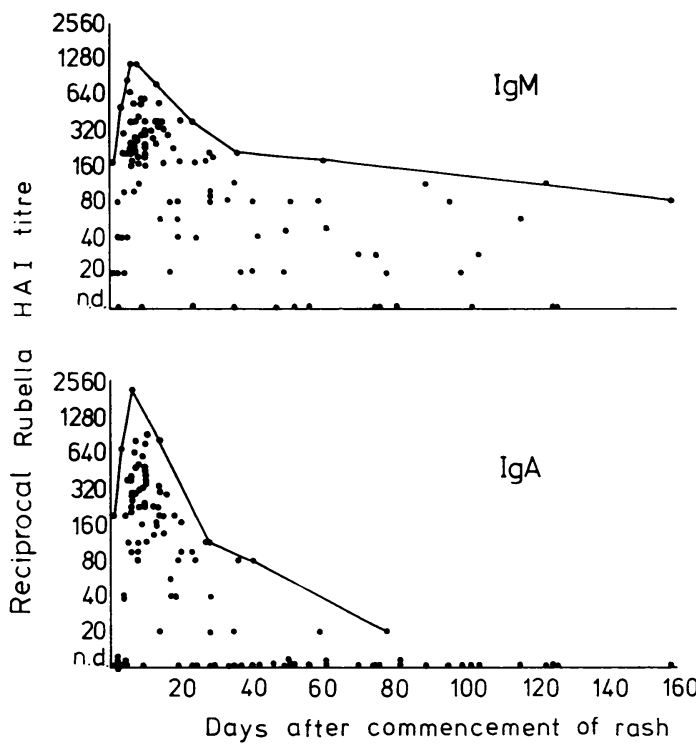

Fig 5 Rubella HAI activity of the IgM and the high molecular weight IgA class in relation to the onset of the rash. $n . d .=$ not detectable.

greater there is a roughly comparable titre of specific high molecular weight IgA antibody. However, in sera with specific IgM antibody titres of less than 1 in 160 there is a tendency for the specific high molecular weight IgA antibody to be markedly less. Indeed 25 out of 37 sera with detectable low titre specific IgM antibody have no detectable specific high molecular weight $\operatorname{IgA}$ antibody, and only one serum contained low titre specific high molecular weight IgA antibody and no detectable specific IgM antibody. The explanation of this lies in the fact that most of the sera with low titre specific IgM antibody are taken a relatively long time after the clinical illness, and specific IgM antibody is detectable for longer after the rubella rash than specific high $\frac{D}{0}$ molecular weight IgA antibody. Of the sera taken more than 40 days after the rash, only two had o specific high molecular weight IgA antibody but 17 had specific IgM antibody (fig 5).

\section{Discussion}

The first of the two peaks of rubella HAI activity found after Sephadex G-200 fractionation of early convalescent sera may contain specific antibody of both the IgM and IgA class and therefore cannot be regarded as an accurate quantitative estimation of the specific IgM content of a serum. However, peak 1 rubella HAI activity is a good index of the presence of specific IgM since specific high molecular weight 
IgA was present in the absence of specific $\operatorname{IgM}$ in only one of the 95 sera tested. Gupta et al (1971) take the rubella HAI titre of the pooled fractions contributing to the ascending limb of the first protein peak after Sephadex G-200 fractionation as an index of the specific IgM content of a serum. This will largely avoid contamination with specific high molecular weight IgA. However, for practical purposes the entire peak 1 rubella HAI activity may be taken as an indication of recent infection since this report agrees with Bürgin-Wolff et al (1971) that specific antibody of the high molecular weight IgA class is detectable for only two to 12 weeks after the acute infection.

Specific IgM has been detected in some of the cases described here for 10 to 11 months after the rash (Pattison, Dane, and Mace, 1975). This is in contrast to the findings of Bürgin-Wolff et al (1971), who found that specific IgM could no longer be detected in sera taken two to three months after the rash. This is at least partly explained by the use of a sensitive HAI test involving overnight virus/fraction reaction time in the present study as opposed to the one-hour reaction time used by Bürgin-Wolff et al (1971). Moreover, fractionation with Bio-Gel A-5M spreads the specific IgM and specific high molecular weight IgA activity over twice as many fractions as Sephadex G-200 (compare figs 1 and 2). This can be largely counteracted by fractionating twice the volume of serum, but even so there were four sera which were specific IgM positive after Sephadex G-200 fractionation but in which specific IgM and/or IgA could be detected after Bio-Gel A-5M fractiona- tion only if a $2.0 \mathrm{ml}$ sample was applied to the column. Three of these sera were late serial specimens from cases in which earlier sera had contained easily detectable specific IgM and high molecular weight IgA after Bio-Gel A-5M fractionation, but the fourth was the only early convalescent specimen available from the case which was IgM positive by either fractionation procedure. It is thus possible that the occasional case will give a false negative result for specific IgM after Bio-Gel A-5M fractionation unless unacceptably large samples are processed.

\section{References}

Best, J. M., Banatvala, J. E., and Watson, D. (1969). Serum IgM and IgG responses in postnatally acquired rubella. Lancet, 2, 65-68.

Bürgin-Wolff, A., Hernandez, R., and Just, M. (1971). Separation of rubella IgM, IgA and IgG antibodies by gel filtration on agarose. Lancet, 2, 1278-1280.

Caul, E. O., Smyth, G. W., and Clarke, S. K. R. (1974). A simplified method for the detection of rubella-specific IgM employing sucrose density fractionation and 2mercaptoethanol. J. Hyg. (Lond.), 73, 329-340.

Gupta, J. D., Peterson, V., Stout, M., and Murphy, A. M. (1971). Single-sample diagnosis of recent rubella by fractionation of antibody on Sephadex G-200 column. J. clin. Path., 24, 547-550.

Pattison, J. R., Dane, D. S., and Mace, J. E. (1975). The persistence of specific IgM after natural infection with rubella virus. Lancet, 1, 185-187.

Pattison, J. R. and Mace, J. E. (1973). A simple, inexpensive gel filtration technique for use in diagnostic serology. J. clin. Path., 26, 309-311.

Pattison, J. R. and Mace, E. (1975). The detection of specific IgM antibodies following infection with rubella virus. J. clin. Path., 28,377-382, 